\title{
An autopsy case of suicide with three knives: a forensic and anatomical discussion
}

\author{
Aleksandar Apostolov' \\ Stanislav Hristov' \\ Dimo Krastev ${ }^{2}$ \\ Manol Kalniev ${ }^{3}$ \\ Nikolai Krastev ${ }^{3}$ \\ 'Medical University - Faculty of \\ Medicine, Department of Forensic \\ Medicine and Deontology, ${ }^{2}$ Medical \\ University - Sofia, Medical College \\ J Filaretova, ${ }^{3}$ Medical University - \\ Sofia, Department of Anatomy and \\ Histology, Sofia, Bulgaria
}

This article was published in the following Dove Press journal:

Research and Reports in Forensic Medical Science

19 September 2013

Number of times this article has been viewed

\begin{abstract}
We present a case of a 30-year-old man who committed suicide, using three knives, after a domestic disturbance in which he repeatedly stabbed his wife. During the inspection of the corpse of the man at the scene, two knives were found embedded in the neck and one in the abdomen. During the autopsy, we found two stab-incised injuries on the anterior surface of the neck in the lower section of the second segment bilaterally, one injury on the left side of the chest, and eleven injuries in the abdomen of the deceased with varying depth. Wound channels ranged from $1.5 \mathrm{~cm}$ to $20 \mathrm{~cm}$. Despite our expectations that some of the major arterial and/or venous vessels in the neck would be cut, we found breaks in only small vessels, nervous structures, sublingual glands, and muscles in the course of the wound channels. In this case, we define such an autopsy finding as rare, or rather, as a rare accident. The inflicted stab-incised injuries as individual anatomical lesions would not lead to certain death. At the time of autopsy we revealed that the fatal injury was in the abdomen, wherein the abdominal aorta was cut. This led to the development of acute blood loss. In the genesis of death, a puncture-incised injury of the left lung was involved, leading to the development of hemopneumothorax. With regards to the possibility of murder, we did not find any cuts or puncture-incised injuries on the body of the deceased man which could be described as "defensive", or such that could have been received while trying to escape. During the police investigation, evidence for the presence of a third person at this domestic incident was not found.
\end{abstract}

Keywords: injuries, types of injuries and digital photography, forensic autopsy, suicide

\section{Introduction}

A review of literature shows that deaths due to injuries with sharp objects are less common than those caused by blunt trauma, gunshot injuries, mechanical asphyxia, and drug poisonings. The frequency of these deaths is different in different countries and regions. The most common way to cause death by acute trauma is murder, followed by suicide and, most rarely, accident. ${ }^{1-3}$

Determining the difference between murder, suicide, and accidental injury is an important issue for forensics. ${ }^{4-7}$ In addition to hanging and self-harm with firearms, self-harm with a sharp object is a commonly used method of suicide, in particular to the throat and neck, which are easily accessible. ${ }^{8-14}$ In some cases, differentiating between the types of damage in the manner of death can be difficult, particularly given the sometimes unconventional atmosphere of the scene of the crime which may not be typical of suicide. ${ }^{5,15,16}$

A very high concentration of vital structures and fascia encased in a small area is typical of the anatomy of the neck. The collection of vascular, nervous, respiratory,

Correspondence: Aleksandar Apostolov Department of Forensic Medicine and Deontology, DNA Laboratory, Medical University - Faculty of Medicine,

2 Zdrave Str., Sofia, Bulgaria, 1431

Tel +35929230412

Fax +35929230412

Email alexa2000@mail.bg
Research and Reports in Forensic Medical Science 2013:3 I-5

(c) (1) (\$) $\odot 213$ Apostolov et al. This work is published by Dove Medical Press Ltt, and licensed under Creative Commons Attribution - Non Commercial (unported, v3.0)

Dovepress

http://dx.doi.org/1 0.21 447/RRFMS.S49768 
and swallowing anatomical units presupposes significant injury of vital structures, as well as potentially fatal complications after invasive trauma. When looking at the feasibility of a penetrating injury to the neck, the area is divided into three zones for anatomic assessment and therapeutic purposes. Zone I includes the region between the clavicle and the cricoid cartilage. Zone II includes the region between the cricoid cartilage and the angle of the mandible and contains the carotid and vertebral arteries, pharynx, internal jugular vein, trachea, and esophagus. Zone III is located between the angle of the mandible and the base of the skull, and includes the upper carotid and vertebral arteries and the pharynx. In the series of predominant stab-cuts, zone I is the most commonly injured area (44\%), followed by zone II (29\%) and zone III (27\%). ${ }^{18,19}$

In other cases of suicide by means of sharp objects, injuries may be multiple and in different anatomic areas of the human body (neck, chest, abdomen) and located in separate groups. ${ }^{20}$

\section{Case report}

According to the police and coroner report of the scene, a 30-year-old man was found dead in his home with stabincised injuries in the abdomen, chest, and neck after having repeatedly stabbed his wife. The wife of the deceased man was found in the living room of the house alive, helpless, and was taken to a specialized hospital; after surgery, she was stabilized and survived.

\section{Autopsy findings External examination}

After external examination of the body of the deceased, 3 traumatic injuries were found. The first injury was on the right cheekbone. There was an arched bruise, open up to $1 \mathrm{~cm}$, pale yellowish, dried, and below the level of the surrounding skin. On the neck, bilaterally under the angle of the mandible, the handles of two almost identical knives stuck from the left and right sides. The cutting edges of the blades faced the midline. The knife in the left side of the neck was a blade, projecting $4 \mathrm{~cm}$ over the handle to the entry into the soft tissues, such that the width of the blade was $18 \mathrm{~mm}$ at skin level. During the autopsy, it was found that the corresponding thrusted part of the blade was $4 \mathrm{~cm}$ in length. The right knife had a portion above the handle of $56 \mathrm{~mm}$. The width of the blade at skin level was $20 \mathrm{~mm}$. The metal part of the blade in the wound channel was $8.2 \mathrm{~cm}$. Wound channels combined components from front to back, from bottom to top, and back to the midline of the described length of penetrating parts of the blades. Local soft tissue structures, sublingual gland and vascular-neural structures were cut; the walls of the wound channels were suffused in the surrounding tissue without the formation of internal blood collection. After removal of the blade on the left, a $15 \mathrm{~mm}$ long wound remained; at the top edge it formed a spike, and the lower edge of the wound was $18 \mathrm{~mm}$ long. The right wound had a $\mathrm{Z}$ shape; dimensions were $12 \mathrm{~mm}$ for the upper, a $14 \mathrm{~mm}$ oblique arm, and an $8 \mathrm{~mm}$ lower arm. The edges of the two wounds were smooth, with sharp corners (Figure 1).

The second wound was in the area of the mammary gland, $4 \mathrm{~cm}$ to the left of midline, and at $123 \mathrm{~cm}$ from the sole. There was a wound without burrs below the third rib, with sharp edges, and $17 \mathrm{~mm}$ long in the horizontal direction. During the autopsy, multi-layer tracing of wound canal ran through soft tissues and entered the chest cavity in the underlying part of the lung, shortly before its front sharp edge penetrated the parenchyma approximately $2 \mathrm{~cm}$ deep, without piercing the opposite pleura. The left chest cavity was tense due to the pneumothorax; in the lowest part there was about $300 \mathrm{~mL}$ of blood.

The third wound was in the area to the left of the anterior abdominal wall, $95 \mathrm{~cm}$ from the heel of the left foot, where there was a bulging handle of a knife. The course of the wound channel was traced in situ as follows: the blade passed through the soft tissues of the abdominal wall, the large shroud was cut to a length of $4.5 \mathrm{~cm}$; it passed below the horizontal portion of the colon, and there was an $8 \mathrm{~cm}$ impairment of the intestinal separator; it then passed behind the rear wall of the base of the intestinal separator, through the front surface and the rear slit of the aorta wall; it ended in the right muscle ileopsoas so that the tip was in the right groin area, $89 \mathrm{~cm}$ from the heel. In the abdominal cavity

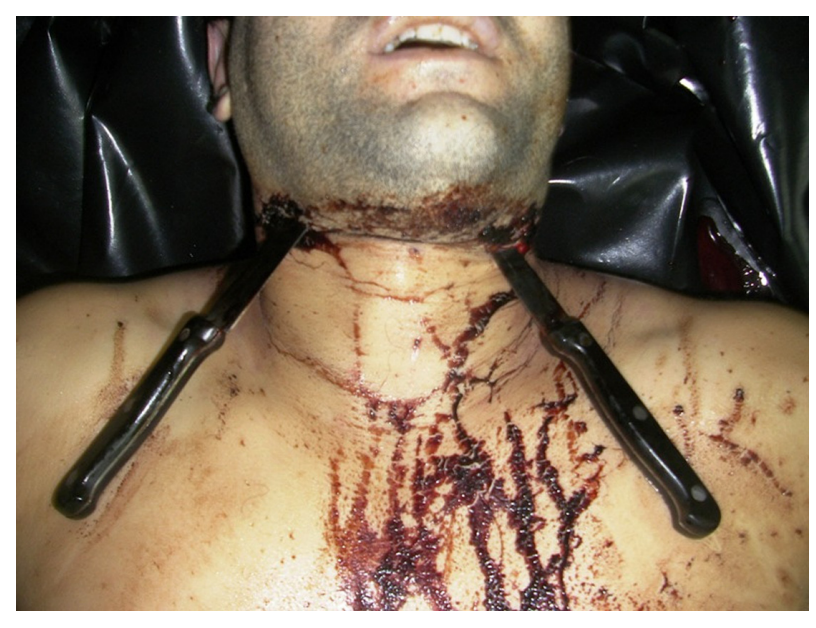

Figure I Detailed picture of the injuries to the neck of the deceased man. 
there was about $1400 \mathrm{~mL}$ dark liquid blood. The knife had a serrated blade, and the cutting part was pointing up. Its entire length was $205 \mathrm{~mm}$ and the width at the base of the handle was $25 \mathrm{~mm}$; the blade fully penetrated the described wound channel. After removal of the knife in the left side of ribs, there appeared at the upper edge a wound of $25 \mathrm{~mm}$, a skin spike top, which went along the bottom edge, and an additional section with a length of $35 \mathrm{~mm}$. In the area below the first cut, along the left half of the abdomen, there were a further 4 shallow wounds, deeply engaging the skin but which did not penetrate into the abdominal cavity and with a length of $13 \mathrm{~mm}, 12 \mathrm{~mm}$, and $8 \mathrm{~mm}$. In the right half of the anterior abdominal wall there were six similar injuries; the highest was to the right and above the navel, another was to the right and slightly below the navel, and the other four were regrouped over the groin and had lengths of $15 \mathrm{~mm}$, $20 \mathrm{~mm}, 8 \mathrm{~mm}$, and $7 \mathrm{~mm}$, recorded top-down. Each wound's depth was no more than $15 \mathrm{~mm}$ and did not penetrate into the abdominal cavity. The genitalia were masculine, without disabilities. The area of the anal opening was clean and intact. Traumatic injuries were absent in the back. Upper and lower limbs were with preserved symmetry, healthy bones in keeping with no abnormal mobility. At the back of the right wrist there were five arched bruises (3-5 mm long), with a pale yellowish color, dried bottom, and below the level of the surrounding skin (Figures 2 and 3).

\section{Internal examination}

When internal examination of the body was conducted, three findings were made. First, cranial membranes were pale pink, without bruising of the bones in the roof of the skull, and foundations were strong. The basal vascular network was

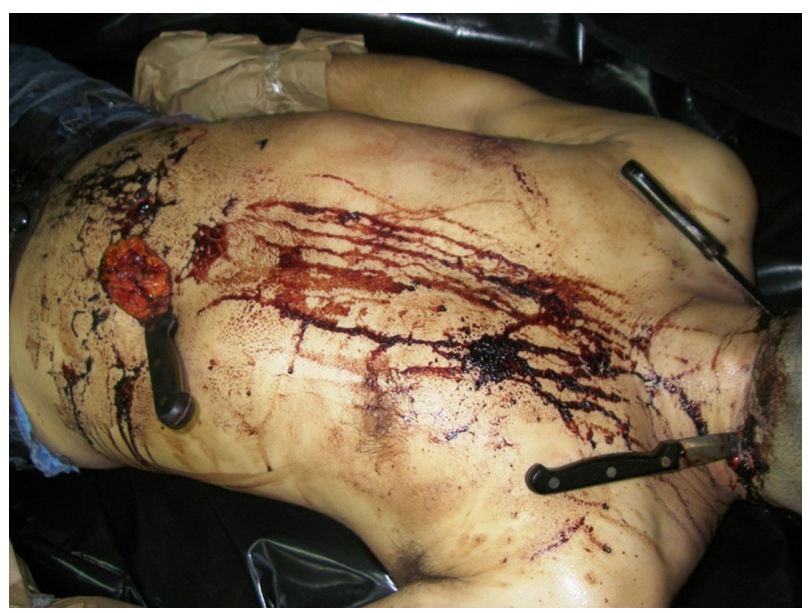

Figure 2 Anatomical location of three blades, stuck in the body of the 30 -yearold man.

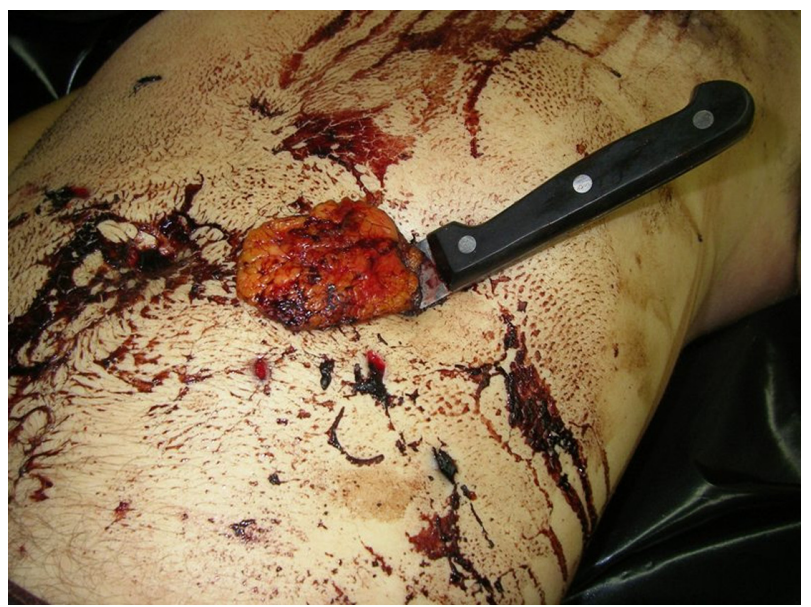

Figure 3 Detailed picture of the injuries in the abdomen of the deceased man.

passable with preserved anatomical configuration. Second, the oral cavity was free of foreign objects. Larynx and hyoid bone were healthy. The described wound channels did not affect the cervical bodies - the trachea and esophagus. The left lung had collapsed to the hilus of the described injury and formed a collection of blood and air in the left chest cavity. The chest had the already described penetrating injury under the third left rib. Thirdly, the abdominal cavity was consistent with the described injuries and blood collection. The great veil had the already described injuries and the liver, spleen, and kidneys were anemic. The pelvis and spine were healthy. The right muscle ileopsoas showed the described cutting in the small pelvis.

As a result of the additional chemical tests of blood samples taken from the body, we confirmed a lack of ethyl alcohol, narcotics, and drugs in the man's system.

\section{Autopsy examination}

At the autopsy examination, several traumatic injuries were found. There was a puncture-incised injury in the left stomach area penetrating into the abdominal cavity. A wound channel formed, reaching the right-lumbar muscle, with a slit along its path of the soft tissues of the abdominal wall, large shroud, colon, small bowel loops intestinal holder, and the back wall of the aorta; there was also a hemorrhage in the abdominal cavity with about $1400 \mathrm{~mL}$ of liquid blood (the injury corresponds to the blade of the knife found stabbed in the abdomen during the examination of the scene). The direction of the multi-layer wound channel combined projection components, front to back, left to right, and slightly top to bottom.

A puncture-incised injury to the left of the chest was noted, with a skin wound in the upper inner quadrant of the 
left breast gland; the shaped wound channel flowed through the third intercostal space, with a slot injury to the front edge of the upper lobe of the lung, accumulation of about $300 \mathrm{~mL}$ of blood, and pneumothorax in the left pleural cavity. The direction of the multi-layer wound channel was traced from front to back and was almost with horizontal orientation.

There were two anatomically bilateral puncture-incised injuries in the neck, located below the lower-jaw angles and with skin lesions on the same level; direction of the multi-layer wound channels tracked combining projection components, front to back, from bottom up and sides, respectively, to the midline. There were injuries to the soft tissues, sublingual glands, and nervous and vascular structures, with depths of $4 \mathrm{~cm}$ for the injury on the left and $8.2 \mathrm{~cm}$ for the injury to the right of the neck (the injuries correspond to the knife blades found embedded in the neck at the scene of the incident).

There were a total of ten superficial stab-incised wounds on the anterior abdominal wall. Four wounds were to the left and six to the right, with depth, engaging skin, and subcutaneous tissue but without penetration into the abdominal cavity.

There were five arched surface scratches on the back of the wrist of the right hand and a bruise in his right cheekbone, acute anemia of the body. There was also a lack of ethyl alcohol, drugs, and medicines in the blood of the dead man. We also noted vertical trickling of blood from the neck at the front surface of the torso and pants, which the deceased was wearing, and smudges from the same material on the soles of the socks.

\section{Discussion}

In this autopsy the death finding was attributed to acute blood loss due primarily to injury to the abdomen, cutting of the abdominal aorta, and the massive bleeding into the abdominal cavity. The established traumatic injuries were due to collision with an object with a sharp point and cutting edge, and fully consistent with the use of knives. From the description of the characteristics of the knives, it is evident they were of three different sizes, both knives in the neck had similar parameter data, and that the blade driven into the abdomen was longer and had a wider blade. All three knives correspond to one and the same kitchen set.

The established puncture-incised injuries on the body could have been caused within a short period of time and with rapid succession, without being able to assess their exact order. Examination showed the surface and grouped abdominal stab-cuts initially caused a deep injury in the abdominal cavity, where the knife stopped. What likely followed was the injury caused to the left mammary gland and then the bilateral damage in the neck, where the other two knives were found. The puncturing in a short period of time caused an acute hemorrhage to develop in the abdominal and thoracic cavities, leading to decreasing intensity and fading qualitative and quantitative range in motion of the body.

The superficial stab-incised injuries of the anterior abdominal wall were grouped and could have been caused by weak application of the top and cutting edges of sharp weapons, such as the knives found. Injury to the abdomen may have been caused when a severe blow with stab-incised arms or the top of the blade resulted in pressure and penetration of the blade to a certain depth. The puncture-incised injury to the left of the chest and neck, on both sides (and likely the last two injuries according to their location and orientation of the wound channel), show that they were inflicted at about the same time. Such injuries may have been inflicted when the deceased man held knives in both hands and thrust into the neck. The injuries were anatomically localized in front of the body, in areas accessible to both arms of the human body, and are of the type that can be self-inflicted by the victim, as noted by other authors. ${ }^{5,15,16}$ It is important to note that there was no evidence that the dead man had a history of psychiatric issues. Our case, presented in the research papers on the topic, is a guide to the mechanisms of such rare, self-inflicted injuries. The use of many self-inflicted stab wounds to the neck, chest, and abdomen has been reported by Kaliszan $\mathrm{M}$ et al as a unique way of committing suicide. ${ }^{20}$

With regards to the possibility of murder, we did not find any cuts or puncture-incised injuries on the body of the deceased man which could be described as "defensive". ${ }^{17}$ A great number of flesh-wounds were also found, which points to the fact that the man was undecided and vouch for doing harm to himself. This rationalization is supported by other authors..$^{3,4,11}$ The police investigation conducted in this case did not find evidence of a third person being present at the time of this domestic incident. The findings of other authors has been that in cases of suicides caused by knives "defensive wounds" have not been found, whereas there are "hesitation marks" located in areas easily accessible with the arms. ${ }^{3-7}$

\section{Conclusion}

Despite our expectations that some of the major arterial and/or venous vessels in the neck would be cut and the presence of the two stab-incised injuries in these areas, only small vessels, nervous structures, sublingual glands, and muscles 
were found damaged in the course of wound channels. We describe these autopsy findings as rare - or rather, as a rare accident. Incised-inflicted stab injuries in the neck, as independent anatomical lesions, would not lead to certain death. The time of autopsy revealed that the fatal injury was in the abdomen, where the abdominal aorta was cut. This led to acute blood loss. In the genesis of death, the puncture-incised injury in the left lung was involved, leading to the development of hemopneumothorax. With regards to the possibility of murder, we did not find any cuts or puncture-incised injuries on the body of the deceased man which could be described as "defensive", or injuries that could be received while trying to escape. During the police investigation on the case, no evidence was found that there was a third person at the scene of the domestic incident.

\section{Disclosure}

The authors report no conflicts of interest in this work.

\section{References}

1. Prahlow JA, Ross KF, Lene WJ, Kirby DB. Accidental sharp force injury fatalities. Am J Forensic Med Pathol. 2001;22(4):358-366.

2. Lyn-Sue J, Siram S, Williams D, Mezghebe H. Epidemiology of trauma deaths in an urban level-1 trauma center predominantly among African Americans - implications for prevention. J Natl Med Assoc. 2006;98(12): 1940-1944.

3. Karch DL, Dahlberg LL, Patel N, et al; Centers for Disease Control and Prevention (CDC). Surveillance for violent deaths - national violent death reporting system, 16 States, 2006. MMWR Surveill Summ. 2009;58(1): $1-44$.

4. DiMaio VJ, DiMaio D. Wounds caused by pointed and sharp-edged weapons. In: Di Maio VJ, Di Maio D. Forensic Pathology. 2nd ed. Boca Raton: CRC Press; 1998:187-228.

5. Karlsson T. Homicidal and suicidal sharp force fatalities in Stockholm, Sweden. Orientation of entrance wounds in stabs gives information in the classification. Forensic Sci Int. 1998;93(1):21-32.
6. Spitz WU. Sharp force injury. In: Spitz WU, Spitz and Fisher's Medicolegal Investigation of Death. 4th ed. Charles C Thomas, Springfield. 2006; p. 532-606.

7. Bohnert M, Hüttemann H, Schmidt U. Homicides by sharp force. In: Tsokos M. Forensic pathology reviews, Humana Press Inc, Totowa. 2005; p. 65-89.

8. Byard RW, Klitte A, Gilbert JD, James RA. Clinicopathologic features of fatal self-inflicted incised and stab wounds: a 20-year study. Am J Forensic Med Pathol. 2002;23(1):15-18.

9. Karlsson T, Ormstad K, Rajs J. Patterns in sharp force fatalities - a comprehensive forensic medical study: Part 2. Suicidal sharp force injury in the Stockholm area 1972-1984. J Forensic Sci. 1988;33(2):448-461.

10. Chadly A, Marc B, Paraire F, Durigon M. Suicidal stab wounds of the throat. Med Sci Law. 1991;31(4):355-356.

11. Fukube $\mathrm{S}$, Hayashi $\mathrm{T}$, Ishida $Y$, et al. Retrospective study on suicidal cases by sharp force injuries. J Forensic Leg Med. 2008;15(3):163-167.

12. Hasekura H, Fukushima H, Yonemura I, Ota M. A rare suicidal case of a ten-year-old child stabbing himself in the throat. J Forensic Sci. 1985;30(4):1269-1271.

13. Jović R. Suicidal knife injuries of the neck. Med Pregl. 1996; 49(7-8):308-312. Croatian.

14. Start RD, Milroy CM, Green MA. Suicide by self-stabbing. Forensic Sci Int. 1992;56(1):89-94.

15. Karger B, Niemeyer J, Brinkmann B. Suicides by sharp force: typical and atypical features. Int J Legal Med. 2000;113(5):259-262.

16. Shetty BS, Padubidri JR, Bhandarkar AM, Shetty AJ, Shetty M. "Atypical Suicidal" cut throat injury - a case report. J Forensic Leg Med. 2009; 16(8):492-493.

17. Solarino B, Buschmann CT, Tsokos M. Suicidal cut-throat and stab fatalities: three case reports. Rom J Leg Med. 2011;19(3):161-166.

18. Demetriades D, Velmahos GC, Asensio JA. Penetrating injuries of the neck. In: Shoemaker W, editor. Textbook of Critical Care. 4th ed. Philadelphia: WB Saunders; 2000:330-337.

19. Demetriades D, Charalambides D, Lakhoo M. Physical examination and selective conservative management in patients with penetrating injuries of the neck. Br J Surg. 1993;80(12):1534-1536.

20. Kaliszan M, Kernbach-Wighton G, Bouhaidar R. Multiple self-inflicted stab wounds to neck, chest and abdomen as a unique manner of suicide. J Forensic Sci. 2010;55(3):822-825.
Research and Reports in Forensic Medical Science

\section{Publish your work in this journal}

Research and Reports in Forensic Medical Science is an international, peer-reviewed, open access journal publishing original research, reports, reviews and commentaries on all areas of forensic medical science. The manuscript management system is completely online and includes a

\section{Dovepress}

very quick and fair peer-review system. Visit http://www.dovepress.com/ testimonials.php to read real quotes from published authors. 